\title{
Hypolipidemic and Hypocholesterolemic Effect of Roselle (Hibiscus sabdariffa L.) Seeds Oil in Experimental Male Rats
}

\author{
Rehab F. M. Ali ${ }^{1}$ and Ayman M. El-Anany ${ }^{2 *}$ \\ ${ }^{1}$ Biochemistry Department, Faculty of Agriculture, Cairo University, Giza, EGYPT \\ ${ }^{2}$ Department of Special Food and Nutrition Researches, Food Tech. Res. Institute; Agricultural Research Center, Giza, EGYPT
}

\begin{abstract}
The current investigation aimed to evaluate the influence of roselle seeds oil (RSO), coconut oil (CNO) and binary mixture of them on serum lipids of experimental rats. Fatty acid composition of native and blended oils was determined. Thirty five male Albino rats (145-160 g) were used throughout this study. The rats were fed AIN-93G diet containing 10\% fat from CNO, RSO, B1 (25\%RSO+ $75 \%$ CNO), B2 (50 $\%$ RSO+ $50 \%$ CNO or B3 (75 \%RSO+ $25 \%$ CNO) for eight weeks. Blood samples were collected at the beginning, every two weeks during the experiment, and at the end of the experiment. At the time of sacrifice, organs weights in relation to their body weights were immediately recorded. Substitution of 25,50 and $75 \%$ of CNO with equal amounts of RSO reduced saturated fatty acids by $16.04,32.58$ and $48.77 \%$, respectively in blended oils. The content of linoleic (C18:2) increased from not detected level in CNO to 9.81, 19.67 and $29.48 \%$ in CNO blended with 25,50 and $75 \%$ of RSO, respectively. The relative liver weights of rats fed CNO was significantly higher than that of those fed RSO and blended oils. Mixing CNO with various levels of RSO attenuates the adverse effect in the relative liver weights which caused by CNO administration. At the end of the experiment, blinding coconut oil with 25,50 and $75 \%$ of roselle oil inhibited the elevation in total cholesterol by $9.69,28.16$ and $36.16 \%$, respectively compared to CNO rats. Rats fed diet containing CNO for 8 weeks had significantly the highest content $(126.49 \mathrm{mg} / \mathrm{dl})$ of low-density lipoprotein cholesterol, while those fed $100 \%$ RSO (as a source of lipids) had the lowest concentration of LDL-C (64.32 mg/dL). Atherogenic index (AI) values of rats submitted B1, B2 and B3 were about 1.12, 1.23 and 1.28 times as low as those of rats fed CNO diet, respectively. The results of this study indicate that roselle seeds oil (RSO) reduces hyperlipidemia and hypercholesterolemia in rats fed diet rich in saturated fatty acids.
\end{abstract}

Key words: roselle seeds oil, saturated fats, blended oils, lipids, serum, liver, weight

\section{Introduction}

The rate of progression of atherosclerosis is influenced by cardiovascular risk factors: tobacco use, an unhealthy diet and physical inactivity (which together result in obesity), elevated blood pressure(hypertension), abnormal blood lipids (dyslipidaemia) and elevated blood glucose (diabetes $)^{1)}$. Dyslipidemia is marked by high values of high levels of low-density lipoproteins cholesterol and low values of high-density lipoproteins cholesterol. This lipid profile in associate with injury of endothelial is a critical event in the most common pathological processes underpinning cardiovascular diseases $(\mathrm{CVD})^{2}$. Several nutritional studies have shown that diet and, in particular, dietary lipids have important roles in controlling the concentra- tions of lipids, cholesterol, and low-density lipoprotein (LDL) cholesterol lipoprotein (a), apolipoprotein (apo)B, and total homocysteine in the plasma ${ }^{3,4)}$. This means that the composition of triacylglycerols (TAG) of lipids has a paramount importance for understanding the nutritional characteristics of the end products ${ }^{5)}$. In the recent times, several techniques have been used to integrate the properties of completely different oils with a view to get an innovative product with the desirable nutritional, physicochemical and technological characteristics ${ }^{6}$. Combining of fats and oils is a well-established method and considered one of the easiest ways; therefore, this technique has been considerably used for combining properties of various fats ${ }^{7}$. The results of clinical experiments revealed that incorpora-

\footnotetext{
*Correspondence to: Ayman M. El-Anany, Department of Special Food and Nutrition Researches, Food Tech. Res. Institute; Agricultural Research Center, Giza, EGYPT

E-mail: aymanelanany82@gimal.com

Accepted August 14, 2016 (received for review June 30, 2016)

Journal of Oleo Science ISSN 1345-8957 print / ISSN 1347-3352 online

http://www.jstage.jst.go.jp/browse/jos/ http://mc.manusriptcentral.com/jjocs
} 
tion of polyunsaturated fats into diet instead of saturated fats reduces $\mathrm{CVD}^{8)}$. Tropical fats contain large amounts of saturated fatty acids in their TAGs. Lauric acid fats such as palm kernel or coconut oil are those having medium and short chain fatty acids (lauric and myristic) as the predominant fatty acid in their oils. These fats contain approximately 50\% lauric acid, from 15 to $20 \%$ myristic acid, and 8-15\% of shorter-chain saturated fatty acids, which are usually more plentiful in coconut oil ${ }^{9)}$. There are marked variations between the impact of individual types of saturated fatty acids on the levels of low density lipoprotein cholesterol (LDL) and high-density lipoproteins cholester$\mathrm{ol}^{10)}$. In this respect, stearic acid (C18:0) has been shown to have no effect on low density lipoprotein cholesterol(LDL) or high-density lipoproteins cholesterol ( HDL) cholesterol or the TC:HDL cholesterol ratio, while, shorter-chain saturated fatty acids have been shown to have a higher LDL cholesterol-raising effect, for example, lauric acid (12:0) increased LDL cholesterol the most, followed by myristic (14:0) and palmitic (16:0) acids. Lauric acid also raised HDL cholesterol most significantly, and it did this disproportionately to TC, so that its replacement of carbohydrate actually led to a significant decrease in the ratio of TC:HDL cholesterol $^{8,10)}$. Roselle is an attractive alternative source of oil. Roselle (Hibiscus sabdariffa L.) belongs to family Malvaceae. It is used in the food and pharmaceutical purposes. Roselle is grown mainly in Upper Egypt (Aswan and Qena governorates) representing around $94 \%$ of total cultivated area in Egypt. In Qena governorate, the total planted area is around $1,150 \mathrm{ha}(45.83 \%)$ which either recently reclaimed area (966 ha) or the old soil of the valley (189 ha). About 1,353 tons out of 2,648 tons (51.1\% of the total production) of dry yield of roselle are produced by Qena governorate $^{11)}$. The amounts of roselle seeds produced that do not use for recultivation process are lacking economic value $^{12)}$. The yield of seeds was recorded at $(500-1000 \mathrm{~kg} /$ acre $)^{13)}$. Roselle seeds contain $9.2-11.6 \%$ moisture, 30.1$31.0 \%$ protein, $5.8-6.9 \%$ total ash, $1.2-4.1 \%$ crude fiber, 36.3-38.1\% total carbohydrates and $21.6-23.2 \%$ total lipids ${ }^{14)}$. Roselle seeds contain high content of oil which looks like cottonseed oil ${ }^{15)}$. Fatty acid profiles of the oils of Egyptian varieties of roselle seeds have been studied by ElAdawy and Khalil ${ }^{14)}$. They reported that the Egyptian cultivars contain $38.8-42.1 \%$ linoleic, $26.3-31.6 \%$ oleic, 20.6 $25.1 \%$ palmitic, $4.6-6.0 \%$ stearic, $0.8-1.0 \%$ lauric, $0.4-$ $0.6 \%$ linolenic, and $0.3-0.5 \%$ myristic acid. This indicates that the unsaturated: saturated fatty acids ratio is $2: 1$ and roselle seed oil belongs to the linoleic/oleic category ${ }^{16)}$. Therefore, the aim of the present investigation was to evaluate the impact of roselle seeds oil, coconut oil and bilateral admixture of them on the serum lipid profile of experimental rats.

\section{Materials}

Dried roselle seeds (Hibiscus sabdariffa. cv. Sabheia17) were gently obtained from a private farm in Aswan Governorate-Egypt. Coconut oil (cold pressed) was purchased from Tropicana Oil Co. Ltd., Nakhon Pathom, Thailand.

\subsection{Oil extraction of Roselle seeds}

Rosella seeds were ground using an electric grinder (Braun Model 1021), to a fine powder. The ground seeds were extracted for $24 \mathrm{hr}$ with n-hexane in a Soxhlet apparatus. Solvent was removed at $50^{\circ} \mathrm{C}$ under reduced pressure using a rotary evaporator. Excess residual moisture is removed by the addition of dried anhydrous sodium sulfate. The oil was centrifuged at $3000 \mathrm{rpm}$ for $30 \mathrm{~min}$ and filtered through Whitman No.1 filter paper. The obtained oil was kept in glass containers, and stored at $-18^{\circ} \mathrm{C}$ until further use.

\subsection{Preparation of Blended oils}

Both roselle seed oil (RSO) and coconut oil (CNO) were blended at the ratios of 0:100, 25:75, 50:50, 75:25 and 100:0 (wt\%), respectively.

The oil blends were individually stirred using a magnetic stirrer for $30 \mathrm{~min}$ at $50^{\circ} \mathrm{C}$ and stored at $-18^{\circ} \mathrm{C}$ until further use.

\section{Fatty acid compositions of blended oils}

Assessing of fatty acids profile was carried out by using capillary gas chromatography (HP 6890). Fatty acid methyl esters (FAMEs) were done according to the procedure described by El-Anany and $\mathrm{Ali}^{8}{ }^{8}$. The FAMEs were identified and separated using a gas chromatograph apparatus equipped with DB-23 capillary column (60 m 30.32 mm 3 $0.25 \mu \mathrm{m}$ film thickness) and a flame ionization detector. The nitrogen flow rate was $3 \mathrm{~mL} / \mathrm{min}$; hydrogen and airflow rates were 40 and, $450 \mathrm{~mL}$ per minute, respectively. The column temperature program was as follow, the temperature was steady at $170^{\circ} \mathrm{C}$ at a rate of $10 \mathrm{~min}$, then the temperature was increased to $192^{\circ} \mathrm{C}$ at a rate of $5^{\circ} \mathrm{C}$ per min. and remain at this degree for another five minutes and then the degree was raised to $220^{\circ} \mathrm{C}$ at a rate of $10^{\circ} \mathrm{C}$ per minute and remain at this degree for three min. MEFAs were identified and measured against a standard mixture of individual fatty acids.

\subsection{Experimental Animals}

Thirty five male Albino rats (Rattus CFT-Wister strain), weighing 145-160 g were obtained from the animal house of Food Technology Research Institute; Agricultural Research Center, Egypt. Rats were grouped ( 7 rats in each group) and housed in polypropylene cages padded with rice husk at environmental conditions, temperature $23 \pm$ 
$2^{\circ} \mathrm{C}$, relative humidity $55 \pm 5 \%$ and 12 hour light/12-hour dark cycle. Food and water were provided ad libitum through the experiment. The rats were fed AIN-93G diet for 8 weeks, which consisted of $10 \%$ fat from [CNO $(100 \%$ coconut oil), RSO (100\% roselle seed oil, $25 \%$ RSO:75\% CNO called (B1), $50 \%$ RSO: $50 \%$ CNO called (B2), or $75 \%$ RSO: 25\% CNO called (B3) ], 20\% casein, 5\% cellulose, $60 \%$ starch, 3.5\% mineral mix, $1.0 \%$ vitamin mix (The formation of the vitamin and mineral mixtures used through this experiment was compatible with that described by A.O.A.C. ${ }^{17)}$. and Reeves et $a l^{18)}$, respectively) , $0.3 \%$ methionine and $0.2 \%$ choline chloride. Daily food intake and weekly body weight were recorded during the experimental period. At the end of experimental period (8 weeks), rats were sacrificed after an overnight fast. The animal experiments conducted according to the recommendations in the Guide for the Care and Use of Laboratory Animals published by the US National Institute of Health (NIH publication No. 85-23, revised 1996). Experimental design and animal handling procedures were approved by ethical committee of the Food Technology Research Institute; Agricultural Research Center, Giza, Egypt. Every effort was done to minimize the number of animals and their suffering.

\subsection{Relative organs weight $(\mathrm{g})$ of rats fed experimental di- ets}

At the time of sacrifice, the hearts, livers and kidneys of rats were identified, removed, rinsed with physiological saline solution and dried by tissue papers. The weights of organs with respect to their body weights were immediately recorded.

\subsection{Blood sampling}

The samples of blood were collected by retro-orbital sinus punction at the beginning of the experiment, every two weeks during the experiment, and at the end of the experimental period ( 8 weeks). The blood of the rats from each group was centrifuged at 3500 at $3500 \mathrm{rpm}$ at $4^{\circ} \mathrm{C}$ for $10 \mathrm{~min}$, the serum stored at $-25^{\circ} \mathrm{C}$ until final analysis.

\subsection{Serum lipid analysis}

Total cholesterol (T-C), high-density lipoprotein cholesterol (HDL-C), low-density lipoprotein cholesterol (LDL-C), and triglycerides (TG), were measured according to the procedures described by El-Anany and $\mathrm{Ali}^{8)}$. On the basis of the serum lipid profile, the atherogenic index was calculated as previously described, using the following formula: $\log (\text { triglycerides }(\mathrm{mg} / \mathrm{dL}) / H D L-c h o l e s t e r o l(\mathrm{mg} / \mathrm{dL}))^{19)}$.

\subsection{Statistical analysis}

Results are expressed as mean \pm standard deviation (SD). Results were analyzed statistically by using and SPSS Version 20.0 (SPSS Inc., Chicago, IL, USA). Scheffe's test was used to determine significant differences between the means of groups. The differences were statistically significant at probability ( $p$ higher than 99\% $(p \leq 0.05)$.

\subsection{Results \& Discussion}

3.6.1 Fatty acid compositions of roselle seed oil (RSO), coconut oil $(\mathrm{CNO})$ and binary mixtures of them

The fatty acids structure of the triglyceride molecule determines the physicochemical properties of the fat and oil. Fatty acid compositions of roselle seed oil(RSO), coconut oil (CNO) and binary mixtures of them are shown in Table 1. There are three main types of fatty acids that can be present in a triglyceride which is saturated, SFAs (Cn:0), monounsaturated, MUFA (Cn:1) and polyunsaturated (PUFA) with two or three double bonds (Cn:2,3). Roselle oil was composed of 39.15 wt. \% linoleic (C18:2), 27.90 wt.\% oleic acid (18:1) , 26.10wt.\% palmitic acid, 4.30 wt.\% stearic $\operatorname{acid}(18: 0), 1.25$ wt.\% lauric acid (C12:0), 0.90 wt.\% myristic acid (C14:0) and 0.40 wt.\% linolenic- $\omega 3$ acid (18:3) (Table 1). This findings indicate that RSO contains 32.55, 27.90 and $39.55 \%$ SFAs, MUFAs and PUFAs, respectively. These results indicate that the saturated: unsaturated fatty acids ratio is $1: 2$, in this regard rosella oil contains low levels of linolenic- $\omega 3$, which has a significant positive effect in oil stability. These findings are in good agreement with those reported by El-Adawy and Khalii ${ }^{14)}$. The content of SFAs of coconut oil was found to be more than that of the unsaturated fatty acids. Total saturated fatty acids content of coconut oil represented $93.5 \mathrm{wt} . \%$ of the total fatty acids. Lauric (C12:0), myristic (C14:0) and palmitic (C16:0) acids were found to be the major saturated fatty acids in coconut oil $42.88,22.07$ and $13.04 \%$, respectively.

Substitution of 25,50 and $75 \%$ of coconut oil with equal amounts of roselle oil reduced saturated fatty acids by $16.04,32.58$ and $48.77 \%$, respectively in blended oils. Health authorities worldwide are encouraging people to decrease their consumption of saturated fatty acids (SFA), trans fatty acids, and cholesterol because of many of investigations which have explained its direct relationship with $\mathrm{CVD}^{20)}$. Blending coconut oil with different levels of roselle oil caused marked increases in MUFAs (oleic $(\mathrm{C} 18: 1))$. The increase in MUFAs (oleic (C18:1)) was gradually and markedly increased with increasing substitution levels. The content of (oleic (C18:1)) was increased from $6.50 \%$ in coconut oil to $11.91,17.30$ and $22.62 \%$ when coconut oil blended with 25,50 and $50 \%$ of roselle oil, respectively. In this regard, the content of linoleic (C18:2) increased from not detected level in coconut oil to 9.81, 19.67 and $29.48 \%$ in coconut oil blended with 25,50 and $75 \%$ of roselle oil, respectively. These increases attributed to the fact that roselle oil contains high amounts of unsaturated fatty acids (Table 1). Vegetable oils rich in both oleic and linoleic acids have been normally used in human nutrition to replace saturated fat, in order to reduce cardiovascular diseases related to atherothrombosis ${ }^{21)}$. 
Table 1 Fatty acid compositions of roselle seed oil (RSO), coconut oil (CNO) and binary mixtures of them.

\begin{tabular}{lccccc}
\hline \multirow{2}{*}{ Fatty acid } & \multirow{2}{*}{ RO } & \multirow{2}{*}{ CO } & \multicolumn{3}{c}{ RO : CO (v/v) } \\
\cline { 4 - 7 } & & & $25: 75$ & $50: 50$ & $75: 25$ \\
\hline Caprylic (C8:0) & nd & 4.12 & 3.04 & 2.00 & 0.92 \\
Capric (C10:0) & nd & 5.13 & 3.88 & 2.51 & 1.26 \\
Lauric (C12:0) & 1.25 & 42.88 & 32.49 & 22.11 & 11.72 \\
Myristic (C14:0) & 0.90 & 22.07 & 16.70 & 11.55 & 6.39 \\
Palmitic (C16:0) & 26.10 & 13.04 & 16.30 & 19.56 & 22.85 \\
Stearic (C18:0) & 4.30 & 6.26 & 5.87 & 5.30 & 4.76 \\
Oleic (C18:1) & 27.90 & 6.50 & 11.91 & 17.30 & 22.62 \\
Linoleic (C18:2) & 39.15 & nd & 9.81 & 19.67 & 29.48 \\
Linolenic (C18:3) & 0.40 & nd & nd & nd & nd \\
\hline SFA & 32.55 & 93.5 & 78.28 & 63.03 & 47.9 \\
MUFA & 27.90 & 6.50 & 11.91 & 17.30 & 22.62 \\
PUFA & 39.55 & - & 9.81 & 19.67 & 29.48 \\
\hline
\end{tabular}

ND, refers to not detected.

SAFA, refers to Saturated Fatty Acids; MUFA, Monounsaturated Fatty Acids; PUFA, Polyunsaturated Fatty Acids.

Table 2 Body weight gain, average food intake and relative weights of organs of rats submitted experimental diets.

\begin{tabular}{cccccccc}
\hline Groups & $\begin{array}{c}\text { Initial body } \\
\text { weight }(\mathrm{g})\end{array}$ & $\begin{array}{c}\text { Final body } \\
\text { weight }(\mathrm{g})\end{array}$ & Weight gain $(\mathrm{g})$ & $\begin{array}{c}\text { Average food } \\
\text { intake }(\mathrm{g} / \text { day })\end{array}$ & $\begin{array}{c}\text { Relative liver } \\
\text { weight }\end{array}$ & $\begin{array}{c}\text { Relative } \\
\text { kidney weight }\end{array}$ & $\begin{array}{c}\text { Relative heart } \\
\text { weight }\end{array}$ \\
\hline RSO & $151.85^{\mathrm{a}} \pm 1.92$ & $258.25^{\mathrm{a}} \pm 4.35$ & $106.40^{\mathrm{a}} \pm 2.33$ & $15.23^{\mathrm{a}} \pm 0.90$ & $2.58^{\mathrm{b}} \pm 0.09$ & $0.36^{\mathrm{a}} \pm 0.02$ & $0.42^{\mathrm{a}} \pm 0.07$ \\
CNO & $152.60^{\mathrm{a}} \pm 0.52$ & $260.50^{\mathrm{a}} \pm 6.80$ & $107.90^{\mathrm{a}} \pm 3.52$ & $15.80^{\mathrm{aa}} \pm 0.63$ & $2.98^{\mathrm{a}} \pm 0.12$ & $0.38^{\mathrm{a}} \pm 0.04$ & $0.47^{\mathrm{a}} \pm 0.08$ \\
B1 & $151.80^{\mathrm{a}} \pm 1.37$ & $256.60^{\mathrm{a}} \pm 3.41$ & $104.80^{\mathrm{a}} \pm 4.12$ & $14.90^{\mathrm{a}} \pm 0.94$ & $2.85^{\mathrm{ab} \pm 0.18}$ & $0.35^{\mathrm{a}} \pm 0.08$ & $0.44^{\mathrm{a}} \pm 0.07$ \\
B2 & $151.50^{\mathrm{a}} \pm 0.87$ & $256.90^{\mathrm{a}} \pm 5.21$ & $105.40^{\mathrm{a}} \pm 2.70$ & $15.30^{\mathrm{a}} \pm 1.25$ & $2.69^{\mathrm{b}} \pm 0.10$ & $0.37^{\mathrm{a}} \pm 0.08$ & $0.43^{\mathrm{a}} \pm 0.09$ \\
B3 & $150.79^{\mathrm{a}} \pm 0.62$ & $257.39^{\mathrm{a}} \pm 6.25$ & $106.60^{\mathrm{a}} \pm 3.88$ & $14.85^{\mathrm{a}} \pm 1.08$ & $2.60^{\mathrm{b}} \pm 0.21$ & $0.36^{\mathrm{a}} \pm 0.09$ & $0.43^{\mathrm{a}} \pm 0.05$ \\
Minimum & & & & & & 0.40 & 0.20 \\
$\begin{array}{c}\text { Significant } \\
\text { Difference }\end{array}$ & 3.579 & 16.287 & 10.29 & 2.98 & 0.22 & \\
\hline
\end{tabular}

Data are expressed as mean \pm SD.

Values followed by the same superscripts are not significantly different $(p<0.05)$.

RSO means rats fed AIN-93G diet containing $10 \%$ of pure roselle seed oil as a source of fat.

CNO means rats fed AIN-93G diet containing $10 \%$ of pure coconut oil as a source of fat.

B1means rats fed AIN-93G diet containing $25 \%$ roselle seed oil: $75 \%$ coconut oil as a source of fat.

B2 means rats fed AIN-93G diet containing $50 \%$ roselle seed oil: $50 \%$ coconut oil as a source of fat.

B3 means rats fed AIN-93G diet containing $75 \%$ roselle seed oil: $25 \%$ coconut oil as a source of fat.

3.6.2 Body weight gain, average food intake and relative weights of organs of rats submitted experimental diets

The initial body weight (g), final body weight (g), weight gain $(\mathrm{g})$ and relative organs weights of rats submitted experimental diets are introduced in Table 2. No significant $(p$ $\geq 0.05$ ) differences were observed in average food intake, weight gain $(\mathrm{g})$, and relative weights of kidney and heart between the study groups (Table 2). However, there were significant $(p \leq 0.05)$ differences between groups in relative liver weight. The relative liver weights of CNO and B1 groups were significantly higher than that of RSO, B2 and B3 groups $(p<0.05)$. The relative liver weights of rats fed diet containing CNO was about 1.15, 1.04, 1.10 and 1.14 times as high as in rats fed RSO, B1, B2 and B3, respectively. In the same time no significant $(p \geq 0.05)$ differences in relative liver weights were observed between rats fed RSO diet and those fed B2 and B3 diets. These findings indicate that mixing coconut oil with various levels of roselle oil attenuates the adverse effect in the relative liver weights 
which caused by coconut oil administration. The liver plays a major role in metabolic regulation of dietary nutrients including fat and carbohydrates. The accumulation of triglycerides in liver parenchymal cells (fatty change, or steatosis), a common liver pathology, is a well-established effect of obesity ${ }^{22)}$. In this regard, Otogawa et $a l{ }^{23)}$ show also that hypercholesterolemia results in inflammation and Kupffer cell hyperplasia in the liver. Studies have also shown that hypercholesterolemia results in severe tubular degeneration and necrosis, protein cast accumulation, and medullary congestion ${ }^{24}$. Several studies show that the composition of dietary fat could play a major role in liver fat accumulation with polyunsaturated fatty acids (PUFAs)adversely ${ }^{25)}$ and saturated fatty acids (SFAs) directly related with liver fat and liver fat biomarkers ${ }^{26}$. Animals fed high fat diets incorporated with PUFAs reduced liver fat accumulation compared to SFA diets ${ }^{27)}$. In this respect, Bjermo et $a l .{ }^{21)}$ indicate that an isocaloric diet rich in PUFAs submitted for ten weeks reduced the content of liver fat and tended to reduce insulin resistance compared to a diet rich in SFAs in individuals with abdominal obesity and type 2 diabetes.

3.6.3 Serum lipids in rats fed diets containing roselle seed oil (RSO), coconut oil (CNO) and binary mixtures of them

Cholesterol and triglycerides as biomarkers, like many other fundamental elements and components of the body, attract the clinical interest In case of their existence in abnormal concentrations. The abnormal levels typically occur because of defects in the synthesis, degradation, and transport of their associated lipoprotein particles ${ }^{10)}$. No significant $(p \geq 0.05)$ differences in the level of T-C were observed among experimental groups from the beginning of the experiment to the fourth week of the experiment. However, marked and significant changes in T-C after administration different type of lipids for 8 weeks. Feeding of diet containing coconut oil induced hypercholesterolemia. The elevation in total cholesterol levels of rats fed CNO was observed at the fourth week of the experiment. At the end of the experiment total cholesterol content of rats fed diet containing $\mathrm{CNO}$ was about 1.75, 1.10, 1.39 and 1.57 times as high as in rats fed RSO, B1, B2 and B3, respectively. These results indicate that the content of oleic acid and linoleic acid of dietary fats is a factor responsible for governing serum total cholesterol levels. The contribution of fatty acids to the cholesterol levels varies with the nature of fatty acids. Therefore, the structure and type of fatty acids in triglyceride molecules, particularly the length of the chain of fatty acids are the major factors which may affect the levels of serum cholesterol ${ }^{28}$. The lowest level of cholesterol content $92.1(\mathrm{mg} / \mathrm{dL})$ at the end of the experiment (8 weeks) was observed for rats fed diet containing roselle seed oil. Blinding coconut oil with 25,50 and $75 \%$ of roselle oil inhibited the elevation in T-C by $9.69,28.16$ and
$36.16 \%$, respectively compared to CNO rats. No significant $(p \leq 0.05)$ differences were observed in the levels of total cholesterol throughout the experiment between rat fed RSO and those rats fed B3 diet which contains $75 \%$ roselle seed oil and $25 \%$ coconut oil as a source of fat. The degree of cholesterol lowering of a dietary lipid cannot be attributed simply to the amount of fat, but also the source of fat ${ }^{29)}$. Both the degree of saturation and chain length of dietary triglyceride have recently been shown to be important in regulating serum and liver cholesterol levels ${ }^{30)}$. In the present study roselle seed oil contains $27.9 \%$ oleic (C18:1) and $39.15 \%$ Linoleic (C18:2) (Table 1). Substitution of SFAs with higher intakes of MUFAs and PUFAs has been reported to reduce the levels of plasma cholesterol ${ }^{311}$. The reduction of blood cholesterol in response to UFA could be caused by changes in several parameters of cholesterol metabolism including fecal excretion of steroids, hepatic synthesis of cholesterol and lipoprotein structure and metabolism ${ }^{32)}$.

LDL, HDL, intermediate-density lipoprotein(IDL), very low-density lipoprotein(VLDL) and chylomicrons are the 5 major classes of lipoproteins. Of these, LDL is the predominant cholesterol-carrying lipoprotein comprising $\sim 75 \%$ of cholesterol carried by non-HDL particles, with the rest $25 \%$ of non-HDL-C in triglyceride-rich particles, which include VLDL, IDL, chylomicrons, and their remnants ${ }^{33}$. Although LDL is necessary in limited quantities (LDL delivers cholesterol to various parts of the body), a high LDL cholesterol level can dramatically increase the risk of a heart attack ${ }^{34)}$. Table 3 shows the changes in the concentrations of serum LDL-C of rats fed diets containing roselle seed oil (RSO), coconut oil (CNO) and binary mixtures of them. At the beginning of experiment there were no significant $(p \geq 0.05)$ differences in the serum level of LDL-C were detected between the experimental groups. However, at the end of the experiment, serum LDL-C levels significantly differed among groups (Table 3 ). Rats fed diet containing coconut oil had significant $(p \leq 0.05)$ and gradual increases in low-density lipoprotein cholesterol (LDL-C) content starting from the fourth week of the experiment and towards the end of the experiment. The highest content $(126.49 \mathrm{mg} / \mathrm{dL}$ ) of low-density lipoprotein cholesterol (LDL-C) was recorded for rats fed CNO diet, while those fed $100 \%$ RSO (as a source of lipids) had the lowest concentration of LDL-C $(64.32 \mathrm{mg} / \mathrm{dL})$ at the end of the experiment. Blinding coconut oil with different concentrations of roselle seed oil caused significant $(p \leq 0.05)$ reductions in LDL-C content. Rats fed B1, B2 and B3 for eight weeks had a serum LDL-C content of 108.50, 89.08 and $72.57 \mathrm{mg} / \mathrm{d}$ $\mathrm{dL}$, respectively. This finding indicate that rats given $25 \%$ $\mathrm{RSO}+75 \% \mathrm{CNO}(\mathrm{B} 1), 50 \% \mathrm{RSO}+50 \% \mathrm{CNO}(\mathrm{B} 2)$, and $75 \% \mathrm{RSO}+25 \% \mathrm{CNO}$ (B3) showed significant decreases in the LDL-C concentrations by $14.22,29.57$ and $42.62 \%$, respectively compared to those given CNO. Substitution of 
Table 3 Serum lipids in rats fed diets containing roselle seed oil (RSO), coconut oil (CNO) and binary mixtures of them.

\begin{tabular}{|c|c|c|c|c|c|c|}
\hline $\begin{array}{c}\text { Blood withdrawal } \\
\text { Period (week) }\end{array}$ & Groups & $\begin{array}{l}\text { Total cholesterol } \\
(\mathrm{mg} / \mathrm{dL})\end{array}$ & $\begin{array}{l}\text { LDLC } \\
(\mathrm{mg} / \mathrm{dL})\end{array}$ & $\begin{array}{c}\text { HDLC } \\
(\mathrm{mg} / \mathrm{dL})\end{array}$ & $\begin{array}{l}\text { triglycerides } \\
(\mathrm{TG})(\mathrm{mg} / \mathrm{dL})\end{array}$ & $\begin{array}{c}\text { Atherogenic } \\
\text { index }\end{array}$ \\
\hline \multirow{5}{*}{0} & RSO & $94.3^{\mathrm{a}} \pm 2.14$ & $64.9^{\mathrm{a}} \pm 1.3$ & $27.11^{\mathrm{a}} \pm 1.1$ & $99.6^{\mathrm{a}} \pm 1.1$ & 0.591 \\
\hline & $\mathrm{CNO}$ & $91.1^{\mathrm{a}} \pm 3.0$ & $63.6^{\mathrm{a}} \pm 2.2$ & $26.62^{\mathrm{a}} \pm 1.3$ & $103.0^{\mathrm{a}} \pm 0.9$ & 0.565 \\
\hline & B1 & $93.2^{\mathrm{a}} \pm 1.9$ & $65.4^{\mathrm{a}} \pm 0.9$ & $26.62^{\mathrm{a}} \pm 0.9$ & $103.1^{\mathrm{a}} \pm 3.1$ & 0.588 \\
\hline & B2 & $91.9^{\mathrm{a}} \pm 0.9$ & $62.1^{\mathrm{a}} \pm 1.1$ & $27.03^{\mathrm{a}} \pm 0.8$ & $101.7^{\mathrm{a}} \pm 1.2$ & 0.575 \\
\hline & B3 & $92.1^{\mathrm{a}} \pm 0.7$ & $63.2^{\mathrm{a}} \pm 1.2$ & $26.25^{\mathrm{a}} \pm 1.4$ & $102.0^{\mathrm{a}} \pm 2.0$ & 0.589 \\
\hline \multicolumn{2}{|c|}{ Minimum Significant Difference } & 5.9 & 2.6 & 3.4 & 5.6 & \\
\hline \multirow{5}{*}{2} & RSO & $94.8^{\mathrm{a}} \pm 1.1$ & $68.4^{\mathrm{a}} \pm 0.7$ & $27.0^{\mathrm{a}} \pm 1.0$ & $100.2^{\mathrm{a}} \pm 0.5$ & 0.586 \\
\hline & $\mathrm{CNO}$ & $91.6^{\mathrm{a}} \pm 1.9$ & $63.9^{\mathrm{b}} \pm 0.9$ & $26.1^{\mathrm{a}} \pm 0.1$ & $103.4^{\mathrm{a}} \pm 2.1$ & 0.568 \\
\hline & B1 & $92.8^{\mathrm{a}} \pm 2.6$ & $64.9^{\mathrm{b}} \pm 1.6$ & $27.0^{\mathrm{a}} \pm 0.8$ & $100.0^{\mathrm{a}} \pm 0.1$ & 0.568 \\
\hline & B2 & $93.0^{\mathrm{a}} \pm 2.6$ & $63.9^{\mathrm{b}} \pm 0.3$ & $27.2^{\mathrm{a}} \pm 0.3$ & $100.8^{\mathrm{a}} \pm 0.9$ & 0.568 \\
\hline & B3 & $91.4^{\mathrm{a}} \pm 2.4$ & $64.1^{\mathrm{b}} \pm 0.7$ & $26.2^{\mathrm{a}} \pm 0.2$ & $99.9^{\mathrm{a}} \pm 0.8$ & 0.576 \\
\hline \multicolumn{2}{|c|}{ Minimum Significant Difference } & 6.7 & 2.9 & 1.8 & 4.55 & \\
\hline \multirow{5}{*}{4} & $\mathrm{CNO}$ & $105.8^{\mathrm{a}} \pm 0.5$ & $90.5^{\mathrm{a}} \pm 1.6$ & $28.0^{\mathrm{a}} \pm 0.1$ & $107.7^{\mathrm{a}} \pm 5.5$ & 0.585 \\
\hline & RSO & $92.2^{\mathrm{b}} \pm 2.6$ & $64.6^{\mathrm{c}} \pm 1.3$ & $27.2^{\mathrm{a}} \pm 0.1$ & $103.5^{\mathrm{a}} \pm 3.1$ & 0.579 \\
\hline & B1 & $96.3^{\mathrm{b}} \pm 0.7$ & $77.1^{\mathrm{b}} \pm 2.5$ & $27.8^{\mathrm{a}} \pm 0.2$ & $105.4^{\mathrm{a}} \pm 0.4$ & 0.578 \\
\hline & B2 & $95.0^{\mathrm{b}} \pm 1.0$ & $68.7^{\mathrm{c}} \pm 2.9$ & $27.5^{\mathrm{a}} \pm 0.1$ & $99.8^{\mathrm{a}} \pm 0.2$ & 0.558 \\
\hline & B3 & $92.5^{\mathrm{b}} \pm 2.2$ & $64.5^{\mathrm{c}} \pm 0.8$ & $27.1^{\mathrm{a}} \pm 0.1$ & $99.9^{\mathrm{a}} \pm 0.6$ & 0.566 \\
\hline \multicolumn{2}{|c|}{ Minimum Significant Difference } & 5.0 & 6.2 & 1.41 & 8.7 & \\
\hline \multirow{5}{*}{6} & $\mathrm{CNO}$ & $142.4^{\mathrm{a}} \pm 3.5$ & $106.4^{\mathrm{a}} \pm 1.3$ & $27.2^{\mathrm{a}} \pm 1.0$ & $126.6^{\mathrm{a}} \pm 6.4$ & 0.667 \\
\hline & RSO & $91.9^{\mathrm{d}} \pm 1.8$ & $64.5^{\mathrm{d}} \pm 1.3$ & $27.2^{\mathrm{a}} \pm 0.1$ & $101.3^{\mathrm{c}} \pm 1.3$ & 0.569 \\
\hline & B1 & $126.4^{\mathrm{b}} \pm 1.5$ & $93.5^{\mathrm{b}} \pm 0.7$ & $28.9^{\mathrm{a}} \pm 1.0$ & $114.3^{\mathrm{b}} \pm 2.4$ & 0.633 \\
\hline & $\mathrm{B} 2$ & $110.2^{\mathrm{c}} \pm 0.7$ & $79.7^{\mathrm{c}} \pm 1.1$ & $27.9^{\mathrm{a}} \pm 0.01$ & $102.7^{\mathrm{c}} \pm 1.6$ & 0.565 \\
\hline & B3 & $91.9^{\mathrm{d}} \pm 1.5$ & $66.4^{\mathrm{d}} \pm 0.5$ & $27.2^{\mathrm{a}} \pm 0.1$ & $101.2^{\mathrm{c}} \pm 1.4$ & 0.570 \\
\hline \multicolumn{2}{|c|}{ Minimum Significant Difference } & 6.2 & 3.28 & 1.9 & 3.5 & \\
\hline \multirow{5}{*}{8} & $\mathrm{CNO}$ & $161.9^{\mathrm{a}} \pm 4.1$ & $126.5^{\mathrm{a}} \pm 0.9$ & $27.4^{\mathrm{a}} \pm 0.7$ & $140.1^{\mathrm{a}} \pm 7.0$ & 0.718 \\
\hline & RSO & $92.1^{\mathrm{e}} \pm 2.1$ & $64.3^{\mathrm{e}} \pm 1.1$ & $28.9^{\mathrm{a}} \pm 1.1$ & $103.6^{\mathrm{c}} \pm 2.4$ & 0.553 \\
\hline & $\mathrm{B} 1$ & $146.2^{\mathrm{b}} \pm 0.73$ & $108.5^{\mathrm{b}} \pm 2.3$ & $28.9^{\mathrm{a}} \pm 1.2$ & $126.7^{\mathrm{b}} \pm 2.5$ & 0.641 \\
\hline & $\mathrm{B} 2$ & $116.3^{\mathrm{c}} \pm 0.3$ & $89.0^{\mathrm{c}} \pm 1.4$ & $28.0^{\mathrm{a}} \pm 0.8$ & $108.0^{\mathrm{c}} \pm 1.3$ & 0.586 \\
\hline & B3 & $103.1^{\mathrm{d}} \pm 0.8$ & $72.5^{\mathrm{d}} \pm 2.1$ & $28.6^{\mathrm{a}} \pm 0.9$ & $104.9^{\mathrm{c}} \pm 2.7$ & 0.563 \\
\hline \multicolumn{2}{|c|}{ Minimum Significant Difference } & 6.4 & 5.0 & 3.0 & 11.4 & \\
\hline
\end{tabular}

Data are expressed as mean \pm SD.

Values given represent means of five determinations.

Values followed by the same letter are not significantly different $(p<0.05)$.

RSO means rats fed AIN-93G diet containing $10 \%$ of pure roselle seed oil as a source of fat.

CNO means rats fed AIN-93G diet containing $10 \%$ of pure coconut oil as a source of fat.

B1means rats fed AIN-93G diet containing25\% roselle seed oil: $75 \%$ coconut oil as a source of fat.

B2 means rats fed AIN-93G diet containing $50 \%$ roselle seed oil: $50 \%$ coconut oil as a source of fat.

B3 means rats fed AIN-93G diet containing75\% roselle seed oil: $25 \%$ coconut oil as a source of fat.

monounsaturated fat (or polyunsaturated fat) for saturated fat similarly reduces LDL cholesterol but does not reduce HDL or increase triglycerides ${ }^{10)}$. Biological studies indicate that conjugated linoleic acid (CLA) may have salutary effects on the Arteriosclerosis ${ }^{35)}$. Rabbits fed for 22 weeks a high fat diet containing conjugated linoleic acid (CLA) at level of $0.5 \mathrm{~g}$ CLA/day have achieved significant reductions in total cholesterol, $\mathrm{LDL}$ cholesterol, the ratio of LDL-C to HDL-C and in triglyceride concentrations after twelve weeks of the beginning of the experiment ${ }^{36)}$. The results obtained from studies on hamsters ${ }^{37)}$ and pigs ${ }^{38)}$ provide support for an impact of dietary fatty acid modification on the number of hepatic LDL receptor (LDLr). These results have shown that SFA decrease while dietary polyunsatu- 
rated fatty acids (PUFA) increase membrane-associated LDL in the liver. Serum triglycerides (TG) concentration of rats was also affected by dietary fat. Table 3 shows the changes in the concentrations of serum TG of rats fed diets containing RSO, CNO and binary mixtures of them. Rats fed CNO had the highest $(p \leq 0.05)$ serum TG concentration of $143.11 \mathrm{mg} / \mathrm{dL}$ at the end of the experiment (8 weeks), while those fed diet containing RSO had significantly the lowest concentration of $103.60 \mathrm{mg} / \mathrm{dL}$. Rats fed diets containing blended oils had significantly lower values of TG compared to those fed CNO diet. TG levels of rats fed B1, B2 and B3 were about 1.12, 1.32 and 1.36 times as low as in rats fed CNO, respectively. In the human body, high concentrations of triglycerides are associated with atherosclerosis and the risk of heart disease and stroke ${ }^{19)}$. WHO recommends preferring unsaturated fatty acids (MUFA, PUFA) from lipid sources to limit the risk of developing non communicable diseases such as diabetes or cardiovascular diseases ${ }^{39)}$. This can either be done with fats rich in unsaturated fatty acids such as rapeseed oil or sunflower oil. It can also be achieved by blending different oils or fats with different fatty acid compositions to lower the SFA and increase the MUFA and PUFA content.

There were no significant differences in initial serum HDL cholesterol concentrations were found between the experimental groups. In the same time, serum HDL cholesterol concentrations of rats fed submitted diets for 8 weeks did not change significantly from baseline (Table 3 ). However, the HDL/TC ratio was decreased significantly for rats fed diet containing coconut oil .Blinding coconut oil with different levels of roselle seed oil attenuates these changes.

Atherogenic index (AI) in recent years has started to gain importance as an indicator of atherosclerosis ${ }^{19)}$. Rats fed diet containing $\mathrm{CNO}$ diet had the highest $\mathrm{AI}$ value. however those fed RSO diet had the lowest value. AI values of rats submitted B1, B2 and B3 were about 1.12, 1.23 and 1.28 times as low as those of rats fed CNO diet, respectively. The results of biological studies suggest that unsaturated fatty acids (MUFA, PUFA) have anti-atherosclerotic properties, improve lipid profile by reducing total cholesterol, LDL and triglycerides ${ }^{8,21)}$.

Because both the Omega- 6 and Omega- 3 polyunsaturated fatty acids (PUFA) are essential fatty acids and reduce the risk of cardiovascular disease ${ }^{40)}$, the above-mentioned changes may be attributed to the deficiency of essential fatty acids in coconut oil. In this respect, Danaei et $a l .{ }^{41}$ ) checked the lifestyle and metabolic risk factors chronic illnesses and reported a deficiency of Omega-3 fatty acids is considered the eighth biggest murderer of American citizens. Therefore, the study suggests to the importance of enhancing consumer knowledge about the risks and hazards of the deficiency of n-3 omega polyunsaturated fatty acids. Actually, several studies have mentioned differ- ent effects of saturated fatty acids on the health. It has been showed that both of lauric acid and myristic acid elevate the levels of total cholesterol, these effects due to the increase in the concentrations of LDL-C, the raise of LDL-C due to an increase in LDL-C and HDL-C levels ${ }^{42,43)}$. The ratio of total cholesterol to HDL cholesterol is a more precise biomarker of heart diseases than the level of LDL -C. Fats and oils that contain high amounts of lauric (C12:0) acid understated the ratio of total to HDL-C. On the other side, myristic, palmitic and stearic acid (C18:0) acids have affected very little effects on this ratio ${ }^{10,44}$. Biological studies have been proven that fats rich in saturated fatty acids raise the concentration of LDL cholesterol by inhibiting the activity of LDL receptors and promoting apolipoprotein apo-B-containing lipoprotein production ${ }^{42)}$. However, monounsaturated and polyunsaturate fatty acids have a positive lipoprotein phenotype by reducing the synthesis and secretion of VLDL cholesterol, reducing the production of apolipoprotein B100 (apo B100) and raising the evacuation of TG-rich lipoproteins ${ }^{8)}$.

\section{References}

1) WHO. WHO Library Cataloguing-in-Publication Data Prevention of cardiovascular disease: guidelines for assessment and management of total cardiovascular risk. World Health Organization, 20 Avenue Appia, 1211 Geneva 27, Switzerland (2007).

2) Bamba, V. Update on screening, etiology, and treatment of dyslipidemia in children. J. Clin. Endocrinol. Metab. 99, 3093-3102 (2014).

3) Schultz, M.B.; Hoffmann, K. Methodological approaches to study dietary pattern in relation to risk factors of CHD and stroke. Br. J. Nutr. 95, 860-869 (2006).

4) Reena, M.B.; Lokesh, B.R. Hypolipidemic effect of oils with balanced amounts of fatty acids obtained by blending and interesterification of coconut oil with rice bran oil or sesame oil. J. Agric. Food Chem. 55, 10461-10469 (2008).

5) Saland, J.M.; Satlin, L.M.; Zalsos-Johnson, J.; Cremers, S.; Ginsberg, H.N. Impaired postprandial lipemic response in chronic kidney disease. Kidney Int. 90, 172180 (2016).

6) Vereecken, J.; Foubert, I.; Smith, W. K.; Sassano, J.G.; Dewettinck, K. Crystallization of model fat blends containing symmetric and asymmetric monounsaturated triacylglycerols. Eur. J. Lipid Sci. Technol. 112, 233245 (2010).

7) Pongsing, W.; Chaoruangrit, A. Improving omega-3 fatty acid content in deep-fat fried sweet potato. Int Food Res. J. 23, 1107-1114(2016).

8) El-Anany, A.M.; Ali, R.F.M. Studies on the hypolipidemic effects of Coconut oil when blended with Tiger 
nut oil and fed to albino rats. Grasas Aceites 63, 303312 (2012).

9) Nusantoro, B.P.; Xanthina1, M.; Kadivar, S.; Yanty, N.A.M.; Dewettinck, K. Enzymatic interesterification of lauric fat blends formulated by grouping triacylglycerol melting points. J. Am. Oil Chem. Soc. 93, 10511062 (2016).

10) Mensink, R.P.; Zock, P.L.; Kester, A.D.; Katan, M.B. Effects of dietary fatty acids and carbohydrates on the ratio of serum total to HDL cholesterol and on serum lipids and apolipoproteins: a meta-analysis of 60 controlled trials. Am. J. Clin. Nutr. 77, 1146-1155 (2003).

11) Hassan, N.; Shimizu, M.; Hyakumachi, M. Occurrence of root rot and vascular wilt diseases in Roselle (Hibiscus sabdariffa L.) in Upper Egypt. Mycobiology 42, 66-72 (2014).

12) Samy, M.S. Chemical and nutritional studies on roselle seeds (Hibiscus sabdariffa L.) . Z. Ernahrungswiss. 19, 47-49 (1980).

13) Abu-Tarboush, H.M.; Ahmed, S.B. Studies on karkade (Hibiscus sabdariffa) protease inhibitors, phytate, in vitro protein digestibility and gossypol content. J. Agric. Food Chem. 56, 15-19 (1996).

14) El-Adawy, T.A.; Khalil, A.H. Characteristics of roselle seeds as a new source of protein and lipid. J. Agric. Food Chem. 42, 1896-1900 (1994).

15) Ahmed, A.W.K.; Hudson, B.J.F. The fatty acid composition of Hibiscus sabdariffa seed oil. J. Sci. Food Agric. 33, 1305-1309 (1979).

16) Mohamed, R.; Fernández, J.; Pineda, M.; Aguilar, M. Roselle (Hibiscus sabdariffa) seed oil is a rich source of $\gamma$-tocopherol. J. Food sci. 72, s207-s211 (2007).

17) A.O.A.C. Official Methods of Analysis of theAssociation of Official Agricultural Chemists. 17th ed. Published by A.O.A.C., Washington, DC (2000) .

18) Reeves, P.G.; Nielsen, F.H.; Fahey, G.C.Jr. AIN-93 Purified diets for laboratory rodents: final report of the American Institute of Nutrition ad hoc writing committee on reformulation of the AIN-76A rodent diet. $J$. Nutr. 123, 1939-1951 (1993).

19) Dobiásová, M.; Frohlich, J. The plasma parameter log (TG/HDL-C) as an atherogenic index: Correlation with lipoprotein particle size and esterification rate in apoB-lipoprotein-depleted plasma (FER (HDL)). Clin. Biochem. 34, 583-588(2001).

20) American Heart Association. Saturated Fats: Available at: http://www.heart.org/HEARTORG/>, (accessed on: 18.09.12) (2011).

21) Bjermo, H.; Iggman, D.; Kullberg J.; Dahlman, I.; Johansson, L.; Persson, L.; Berglund, J.; Pulkki, K.; Basu, S.; Uusitupa, M.; Rudling, M.; Arner, P.; Cederholm, T.; Ahlström, H.; Risérus, U. Effects of n-6 PUFAs compared with SFAs on liver fat, lipoproteins, and inflammation in abdominal obesity: a randomized controlled trial. Am. J. Clin. Nutr. 95, 1003-1012 (2012).

22) Mezey, E. Fatty Liver. in Schiff's Diseases of the Liver (Schiff, E.R.; Sorrell, M.F.; Maddrey, W.C. eds.). Philadelphia, Lippincott-Raven, pp. 1185-1197(1999).

23) Otogawa, K.; Kinoshita, K.; Fujii, H.; Sakabe, M.; Shiga, R.; Nakatani, K.; Ikeda, K.; Nakajima, Y.; Ikura, Y.; Ueda, M.; Arakawa, T. ; Hato, F.; Kawada, N. Erythrophagocytosis by liver macrophages (Kupffer cells) promotes oxidative stress, inflammation, and fibrosis in a rabbit model of steatohepatitis: implications for the pathogenesis of human nonalcoholic steatohepatitis. Am. J. Pathol. 170, 967-980 (2007).

24） Yang, D.W.; Jia, R.H.; Yang, D.P.; Ding, G.H.; Huang, C.X. Dietary hypercholesterolemia aggravates contrast media-induced nephropathy. Chin. Med. J. (Engl) 117, 542-546 (2004).

25) Petersson, H.; Riserus, U.; McMonagle, J.; Gulseth, H.L.; Tierney, A.C.; Morange S ; Helal, O.; Shaw, D.I.; Ruano, J.A.; López-Miranda, J.; Kieć-Wilk, B.; Gołąbek, I.; Blaak, E.E.; Saris, W.H.; Drevon, C.A.; Lovegrove, J.A.; Roche, H.M.; Basu, S. Effects of dietary fat modification on oxidative stress and inflammatory markers in the LIPGENE study. Br. J. Nutr. 104, 1357-1362 (2010).

26) Allard, J.P.; Aghdassi, E.; Mohammed, S. Nutritional assessment and hepatic fatty acid composition in nonalcoholic fatty liver disease (NAFLD) : a cross-sectional study. J. Hepatol. 48, 300-307 (2008).

27) Crescenzo, R.; Bianco, F.; Falcone, I. et al. Hepatic mitochondrial energetic during catch-up fat with high-fat diets rich in lard or safflower oil. Obesity 20, 1763$1772(2012)$.

28) Lanier, J.S.; Corl, B.A. Challenges in enriching milk fat with polyunsaturated fatty acids. J. Anim. Sci. Biotechnol. 6, 26 DOI 10.1186/s40104-015-0025-0 (2015).

29) Nwokolo, E.; Kitts, D.D.; Kanhai, J. Serum and liver lipids of rats fed rubber seed oil. Plant Food. Hum. Nutr. 38, 145-153 (1988).

30) Clifford, A.J.; Smith, L.M.; Creveling, R.K.; Hamblin, C.L.; Clifford, C.K. Effects of dietary triglycerides on serum and liver lipids and sterol excrection of rats. $J$. Nutr. 116, 944-956 (1986).

31） Ooi, Y.P.; Weng, S.J.; Jang, L.Y.; Low, L.; Seah, J.; Teo, S.; Ang, R.P.; Lim, C.G.; Liew, A.; Fung, D.S.; Sung, M. Omega-3 fatty acids in the management of autism spectrum disorders: findings from an open-label pilot study in Singapore. Eur. J. Clin. Nutr. 69, 969-971 (2015).

32) Henriques, G.S.; Helm, C.V.; Busato, A.P.; Simeone, M.L.F. Lipid profile and glycemic response of rats fed on a semi-purified diet supplemented with Agaricus brasiliensis mushroom. Acta Sci. Health Sci. 38, 71-79 (2016).

33) Varbo, A.; Benn, M.; Nordestgaard, B.G. Remnant cho- 
lesterol as a cause of ischemic heart disease: evidence, definition, measurement, atherogenicity, high risk patients, and present and future treatment. Pharmacol. Ther. 141, 358-367 (2014).

34) Escott-Stump, S.; Mahan, L.K. Krause's Food, Nutrition, \& Diet Therapy. 11th ed. Saunders, Philadelphia, PA (2004).

35) Bruen, R.; Fitzsimons, S.; Belton, O. Atheroprotective effects of conjugated linoleic acid. Br. J. Clin. Pharmacol. DOI:10.1111/bcp.12948(2016).

36) Lee, N.K.; Kritchevsky, D.; Pariza, M.W. Conjugated linoleic acid and atherosclerosis in rabbits. Atherosclerosis 108, 109 (1994).

37) Horton, J.D.; Cuthbert, J.A.; Spady, D.K. Dietary fatty acids regulate hepatic low density lipoprotein (LDL) transport by altering LDL receptor protein and mRNA levels. J. Clin. Invest. 92, 743-749(1993).

38) Mustad, V.A.; Ellsworth, J.; Cooper, A.D.; Kris-Etherton, P.M.; Etherton, T.D. Dietary linoleic acid increases and palmitic acid decreases hepatic LDL receptor protein and mRNA abundance in young pigs. J. Lipid
Res. 37, 2310-2323 (1996).

39) WHO. Healthy diet, Fact sheet N394, Geneva: World Health Organization; Updated September (2015). www.who.int/mediacentre/factsheets/fs394/en.

40) Willett, W.C. Dietary fats and coronary heart disease. J. Intern. Med. 272, 13-24(2012).

41) Danaei, G.; Ding, E.L.; Mozaffarian, D.; Taylor, B.; Rehm, J.; Murray, C.J.L.; Murray, M. Comparative risk assessment of dietary, lifestyle, and metabolic risk factors. PLoS Med. 6, doi.org/10.1371/journal.pmed. 1000058 (2009).

42) Denke, M.A.; Grundy, S.M. Comparison of effects of lauric acid and palmitic acid on plasma lipids and lipoproteins. Am. J. Clin. Nutr. 56, 895-898(1992).

43) Zock, P.L.; de Vries, J.H.M.; Katan, M.B. Impact of myristic acid versus palmitic acid on serum lipid and lipoprotein levels in healthy women and men. Arterioscler. Thromb. Vasc. 14, 567-575(1994).

44) Lawrence, G.D. Dietary fats and health: Dietary recommendations in the context of scientific evidence. Adv. Nutr. 4, 294-302(2013). 